\title{
Cemento-Ossifying Fibroma of the Maxilla: A Case Report
}

\author{
Piyush Verma $\cdot$ Praveen K. Rathore $\cdot$ \\ Sumit Mrig $\cdot$ Manisha Pal $\cdot$ Ankush Sial
}

Received: 26 July 2008/Accepted: 15 August 2008/Published online: 19 April 2011

(C) Association of Otolaryngologists of India 2011

\begin{abstract}
We report a case of very large ossifying fibroma of the maxilla in a 22-year-old male. It is a bony tumour of the maxilla of possibly odontogenic origin with aggressive behavior and high tendency for recurrence.
\end{abstract}

Keywords Cemento-ossifying fibroma $\cdot$ Maxilla

\section{Introduction}

Cemento-ossifying fibroma (COF) is considered a benign osseous tumour, very closely related to other lesions such as fibrous dysplasia, cementifying periapical dysplasia or amento-osseous dysplasia. The 1992 WHO classification groups it under a simple designation COF with two histologic types, cementifying fibroma and ossifying fibroma, that may be radiologically undistinguishable [1].

\section{Case Report}

A 22 year old presented to the outpatient clinic with a large swelling over the hard palate and molar and premolar region. The patient stated that the mass had first appeared 2 years ago and had been increasing in size since then. Patient had difficulty in mastication and the tumour used to bled on touch, but he had no complaints of pain, dysphagia. There was no other significant past history. The physical examination revealed a large circumscribed mass involving

P. Verma $(\bowtie)$ - P. K. Rathore · S. Mrig · M. Pal · A. Sial Maulana Azad Medical College, Bahadur Shah Zafar Marg, New Delhi 110002, India

e-mail: doctor_piyushverma@yahoo.com the anterior part of hard palate in the midline and extending bilaterally displacing the upper molars and premolars and had effaced the gingivolabial sulcus (Fig. 1). On its outer surface there were multiple pus points and was non tender and bleed on touching.

The contrast enhanced CT scan showed expansile lytic lesion with osseous fragments involving the anterior $1 / 3$ of the hard palate and alveolar ridge (Fig. 2). Anteriorly, it involves the right nasal passage abutting the inferior turbinate and blocking the airway. COF of aggressive type was diagnosed on biopsy and patient underwent resection of the tumour via mid facial degloving approach (Fig. 3). The post operative period was uneventful and patient was referred to prosthodontics for correction of dental deformity. A histopathological examination showed haphazardly arranged spindle cells with monomorphic nuclei; stoma showed laying down of irregularly outlined osteoid. A small focus of psammoma like calcification was seen.

\section{Discussion}

COF is a bony tumour of the maxilla of possible odontogenic origin and is believed to derive from the cells of the periodontal ligament [2-4]. This is a layer of fibrous connective tissue surrounding the roots of the teeth. This neoplasm occurs in patients of wide age range, with greatest number of cases between third and fourth decade of life. There is a definite female predilection $[5,6]$ with female to male ratio of 5:1. The mandibular molar and premolar is the common site. Aggressive lesions usually involve the maxillary antrum. COF of the head and neck is described radiographically as a well-circumscribed expansile lesion with calcified matrices in the maxilla and mandible. Though central COF of the mandible are 

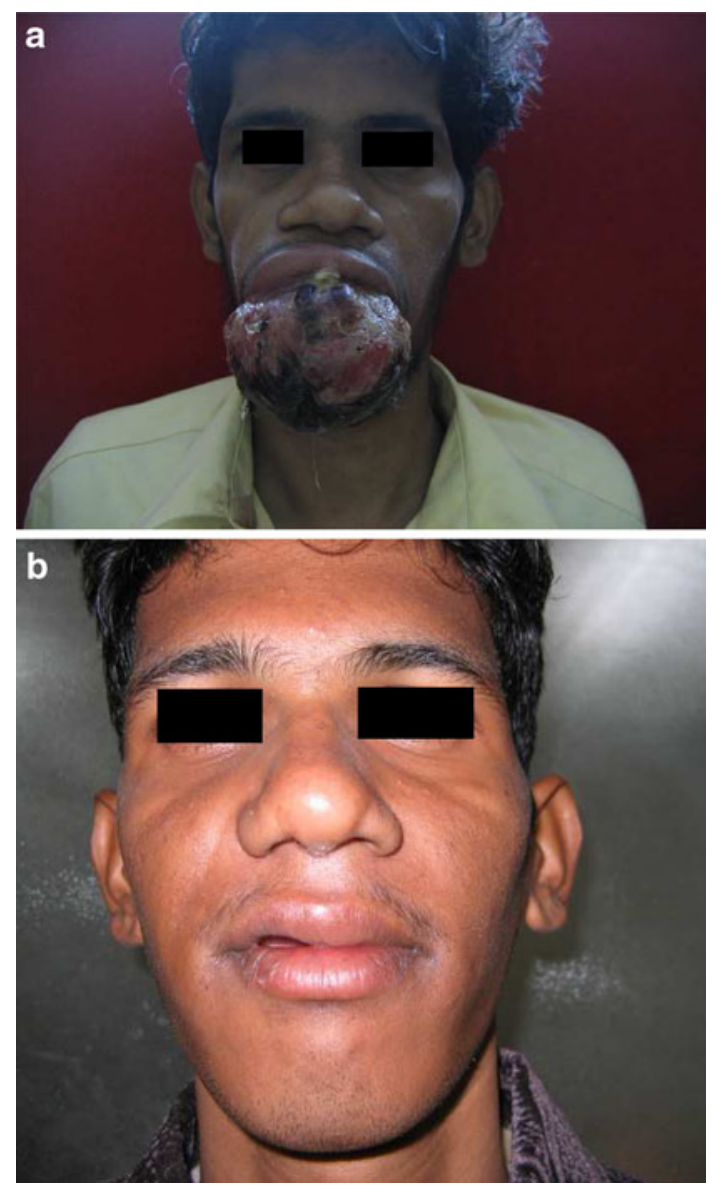

Fig. 1 Clinical photograph of the patient a Pre-operative, b Postoperative

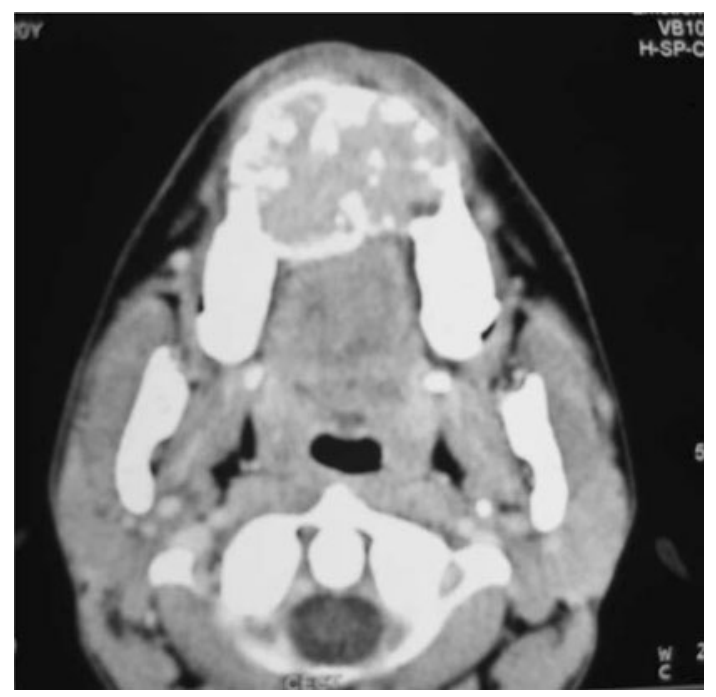

Fig. 2 CT scan (axial cut) showing the lytic lesion with osseous fragments involving the anterior $1 / 3$ of the hard palate and alveolar ridge

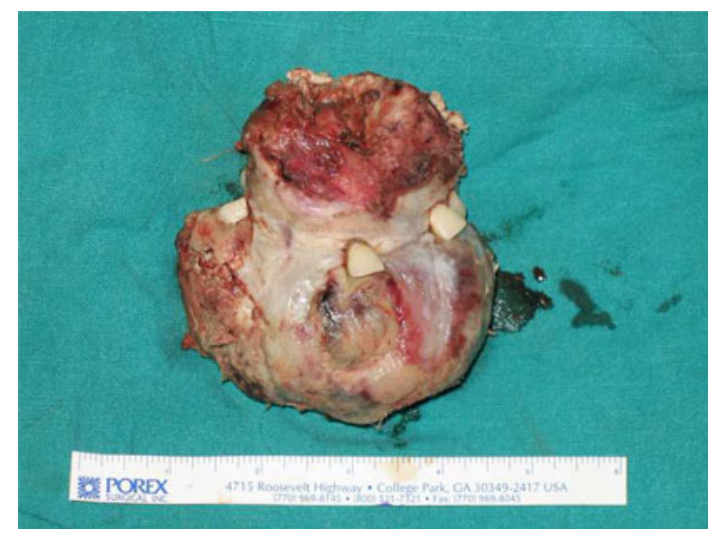

Fig. 3 Resected specimen

common, antral COF of the maxilla is rare and only few cases have been reported in the literature.

Central COF is a distinct form of benign fibro osseous lesion of the mandible and maxilla. They are thought to arise from the periodontal ligament and are composed of varying amount of cementum, bone, and fibrous tissue. The hybrid name of central cemento-ossifying fibroma is used because there is a spectrum of fibro osseous lesion, that arises from the periodontal ligament, varying from those only with cementum to those with only deposition of bone [7]. COF occurs more commonly in the females than males. They arise in the mandible in 62 to $89 \%$ of patients with $77 \%$ of them occurring in the premolar region, most of them are diagnosed between the 20 to 40 years of age [7]. When the tumour arises in the children it is usually of the aggressive type and is called as juvenile aggressive $\mathrm{COF}$ and is usually of vascular type on histological examination.

Maxillary lesions are large at the time of presentation, indicating the capacity of the tumour to expand freely within the maxillary sinus. The pathological examination showed a benign fibro osseous proliferation composed of bony spicules and spherules admixed with a fibrous stroma. The most distinct component was the presence of calcified psammomatoid bodies. The lesion was hypocellular with absence of mitotic activity; this histological picture was consistent with the COF of the maxilla. The maxillary COF tends to display greater degree of immaturity than that seen in mandibular lesions.

Radiographically, COF may follow different patterns based on the amount of mineralized tissue. It presents as a well demarcated unilocular lesion that might have a different degree of opacification. It can cause root resorption and tooth displacement [8].

The differential diagnosis of COF includes other lesions that contain radiopacities within a well-defined radiolucent mass. These lesions are chondrosarcoma and osteosarcoma, fibrous dysplasia, odontogenic cysts, squamous cell 
carcinoma, Grolin's cyst (calcifying odontogenic cyst), and Pindborg tumour (calcifying epithelial tumour). The welldefined borders of COF help differentiate it from aggressive sarcomas and carcinomas. Fibrous dysplasia has a typical ground glass appearance. Grolin cysts and Pindborg tumours are difficult to distinguish and can only be done on histologic examination.

The recommended treatment for COF is complete excision of the tumour. The entire tumour should be removed along with the involved site. Central ossifying fibromas are easy to resect but that involving the maxilla is difficult to resect completely.

Recurrence has been reported in as many as $28 \%$ of patients with mandibular lesions and is unknown in cases involving the maxilla, but it is likely to be higher because of the greater difficulty of surgical removal and large size of the lesion at the time of presentation $[7,9]$.

\section{References}

1. Kramer IRH, Pindborg JJ, Shear M (1992) Neoplasm and other lesions related to bone. In: WHO Histologic typing of odontogenic tumours. Berlin, Springer-Verlag, pp 28-31
2. Cohn HC, MacPhearson TA, Barnes L, Kennerdel JS (1982) Cemento-ossifying fibroma of the ethmoidal sinus manifesting as proptosis. Ann Ophthalmol 14:173-175

3. Fujimoto Y, Katoh M, Miyata M, Kawai T (1987) Cystic cementoossifying fibroma of the ethmoidal cells (a case report). J Laryngol Otol 101:946-952

4. Bradman G, Werner JA, Janig U (1997) Cemento-ossifying of the pre mastoid region: case report and review of literature. J Laryngol Otol 111:152-155

5. El Mofty SK (1999) Cemento-ossifying fibroma and benign cementoblastoma. Semin Diagn Pathol 16:302-307

6. Macdonald DS (1998) Cemento-ossifying fibromas in the jaw of honkong Chinese. Dentomaxillofac Radiol 27:298-304

7. Kuta AJ, Macdonald W, Kauger GE (1995) Central cementoossifying fibroma of the maxillary sinus: A review of six cases. Am J Neuroradiol 16:1282-1286

8. Manganaro AM, Ragno JR, Karlos V (1997) Mixed radiolucent radio opaque lesions of the mandible. J Oral Maxilofac Surg 55:1456-1459

9. Sanchis JM, Pennarrocha M, Balaguer JM, Camacho C (2003) Cemanto-ossifying fibroma of the mandible: A presentation of two cases and a review of literature. Med Oral 9:69-73 